\title{
Need to update cardiological guidelines to prevent COVID-19 related myocardial infarction and ischemic stroke
}

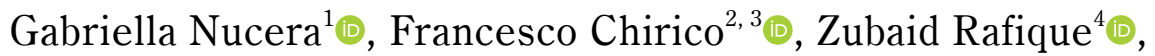 \\ Natasza Gilis-Malinowska ${ }^{5}$, Aleksandra Gasecka ${ }^{6}{ }^{\circ}$, Nataliia Litvinova ${ }^{7}$,

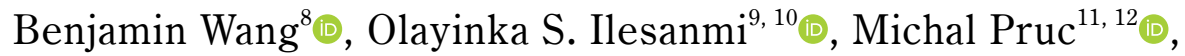 \\ Milosz J. Jaguszewski ${ }^{5}$ (D), Lukasz Szarpak ${ }^{11,13,14}$ (1) \\ ${ }^{1}$ Department of Emergency, Fatebenefratelli Hospital, ASST Fatebenefratelli and Sacco, Milan, Italy \\ ${ }^{2}$ Post-graduate School of Occupational Health, Università Cattolica del Sacro Cuore, Rome, Italy \\ ${ }^{3}$ Health Service Department, Italian State Police, Ministry of the Interior, Milan, Italy \\ ${ }^{4}$ Henry JN Taub Department of Emergency Medicine, Baylor College of Medicine, Houston, TX, United States \\ ${ }^{5}$ First Department of Cardiology, Medical University of Gdansk, Poland \\ ${ }^{6}$ Laboratory of Experimental Clinical Chemistry, Amsterdam University Medical Center, \\ Amsterdam, the Netherlands \\ ${ }^{7}$ European Medical School, International European University, Kiev, Ukraine \\ ${ }^{8}$ UC Davis Graduate School of Management, Davis, CA, United States \\ ${ }^{9}$ Department of Community Medicine, College of Medicine, University of Ibadan, Oyo State, Nigeria \\ ${ }^{10}$ Department of Community Medicine, College of Medicine, University College Hospital, \\ Ibadan, Oyo State, Nigeria \\ ${ }^{11}$ Polish Society of Disaster Medicine, Warsaw, Poland \\ ${ }^{12}$ Institute of Outcomes Research, Polonia University, Czestochowa, Poland \\ ${ }^{13}$ Research Unit, Maria Sklodowska-Curie Bialystok Oncology Center, Bialystok, Poland \\ ${ }^{14}$ Institute of Outcomes Research, Maria Sklodowska-Curie Medical Academy, Warsaw, Poland
}

This paper was guest edited by Prof. Togay Evrin

Novel coronavirus disease caused by severe acute respiratory syndrome coronavirus 2 (SARS$-\mathrm{CoV}-2$ ) has become a challenge for the health care system worldwide and continues to have a significant impact on both the lives of people around the world and the functioning of medical services $[1,2]$. One-third of patients hospitalized due to severe coronavirus disease 2019 (COVID-19) develops macrovascular thrombotic complications, including venous thromboembolism, myocardial injury/ /infarction, and stroke [3]. Both the risk of stroke and myocardial infarction caused by COVID-19 has posed huge pressures on medical services during the pandemic. Beyond the COVID-19 pandemic period itself, the post-pandemic effects can also be dramatic for healthcare systems, because rehabilitation services shall manage patients recovering from severe COVID-19 with post-intensive care syndromes, which results in physical deconditioning and cognitive impairments, patients with comorbid conditions, and other patients requiring physical therapy during the outbreak.

Evidence from a study among 86,742 COVID-19 cases revealed an increase in rates of

Address for correspondence: Dr. Francesco Chirico, Health Service Department, Italian State Police, Ministry of the Interior, Via Umberto Cagni, 2120162 Milano, Italy, e-mail: francesco.chirico@unicatt.it

Received: 16.08.2021 Accepted: 19.08.2021 Early publication date: 8.10.2021

This article is available in open access under Creative Common Attribution-Non-Commercial-No Derivatives 4.0 International (CC BY-NC-ND 4.0) license, allowing to download articles and share them with others as long as they credit the authors and the publisher, but without permission to change them in any way or use them commercially. 
heart attack by nearly 5 times. In addition, the risk of a first stroke due to blockage of blood vessels increased three to six times which was sustained for at least 4 weeks [4].

Importantly, the study did not include people who had previously had a heart attack or stroke in the past, which may suggest that the risk of another heart attack or stroke in people who have had one may probably be even significantly higher.

COVID-19 affects the inner surfaces of the veins and arteries, causing inflammation of blood vessels (endothelium) followed by damage to very small vessels and culmination as blood clots, leading to disturbances in blood flow to the heart or blood clots in other parts of the body. This results in a stroke or heart attack.

Direct myocardial injury by viral involvement of cardiomyocytes, indirect and direct inflammatory damage, $\mathrm{O}_{2}$ supply-demand imbalance, and increase of atherothrombotic events due to inflammatory destabilization of atheromatous plaques may result in myocardial infarction and/or heart failure [5-7].

Acute cerebrovascular disease, particularly ischemic stroke is caused by involvement of large vessel occlusion, multi-territory stroke, and otherwise uncommonly affected vessels. On the contrary, small-vessel brain disease, cerebral venous thrombosis, and intracerebral hemorrhage appear to be less frequent [8].

Hypertension seems to enhance the inflammatory profile in patients with SARS-CoV-2 infection [5], and hyperglycemia might modulate immune and inflammatory responses, thus predisposing patients to severe COVID-19 and possible lethal outcomes [9]. It is not a coincidence that hypertension (56.6\%) and diabetes (33.8\%) are the most prevalent comorbidities among individuals with COVID-19, who require hospitalization [5].

To date, effective therapies against COVID-19 are not currently available. All the governments have invested their efforts on vaccines, which are considered as the only effective weapons to curb the COVID-19 pandemic. However, the onset of new SARS-CoV-2 variants, the high vaccine hesitancy rates in rich countries, and the huge vaccination rate disparity between rich and poor countries are delaying the mass vaccination campaign worldwide.

Therefore, data on COVID-19-related myocardial infarction and ischemic stroke are worrying and indicate the need to implement prophylaxis in the form of anticoagulants, which could be used routinely in the event of thrombosis caused by COVID-19. For this reason, cardiological guidelines for the treatment of post-COVID-19 syndromes should also be established, to drive healthcare workers especially when high-risk categories such as older, obese and patients affected by comorbidities are affected by COVID-19 infection.

This could reduce the incidence and mortality associated with COVID-19-related acute myocardial injury or stroke, and prevent severe forms of COVID-19 infection associated with coagulation changes and the risk of thrombosis, particularly in the features of pulmonary embolism and acute respiratory distress syndrome.

\section{Conflict of interest: None declared}

\section{References}

1. Dzieciatkowski T, Szarpak L, Filipiak KJ, et al. COVID-19 challenge for modern medicine. Cardiol J. 2020; 27(2): 175-183, doi: 10.5603/CJ.a2020.0055, indexed in Pubmed: 32286679.

1. Ruetzler K, Szarpak L, Filipiak K, et al. The COVID-19 pandemic - a view of the current state of the problem. Disaster Emerg Med J. 2020, doi: 10.5603/demj.a2020.0015.

2. Gasecka A, Pruc M, Kukula K, et al. Post-COVID-19 heart syndrome. Cardiol J. 2021; 28(2): 353-354, doi: 10.5603/ cj.a2021.0028, indexed in Pubmed: 33645626.

3. Katsoularis I, Fonseca-Rodríguez O, Farrington P, et al. Risk of acute myocardial infarction and ischaemic stroke following COVID-19 in Sweden: a self-controlled case series and matched cohort study. Lancet. 2021; 398(10300): 599-607, doi: 10.1016/ S0140-6736(21)00896-5, indexed in Pubmed: 34332652.

4. Azevedo RB, Botelho BG, Hollanda JV, et al. Covid-19 and the cardiovascular system: a comprehensive review. J Hum Hypertens. 2021; 35(1): 4-11, doi: 10.1038/s41371-020-0387-4, indexed in Pubmed: 32719447.

5. Paprocki M. Nonsteroidal anti-inflammatory drugs (NSAIDs) in COVID-19 patient. Disaster Emerg Med J. 2020, doi: 10.5603/ demj.a2020.0016.

6. Gąsecka A, Filipiak KJ, Jaguszewski MJ. Impaired microcirculation function in COVID-19 and implications for potential therapies. Cardiol J. 2020; 27(5): 485-488, doi: 10.5603/CJ.2020.0154, indexed in Pubmed: 33165898.

7. Vogrig A, Gigli GL, Bnà C, et al. Stroke in patients with COVID-19: Clinical and neuroimaging characteristics. Neurosci Lett. 2021; 743: 135564, doi: 10.1016/j.neulet.2020.135564, indexed in Pubmed: 33352277.

8. Lim S, Bae JH, Kwon HS, et al. COVID-19 and diabetes mellitus: from pathophysiology to clinical management. Nat Rev Endocrinol. 2021; 17(1): 11-30, doi: 10.1038/s41574-020-00435-4, indexed in Pubmed: 33188364. 